\title{
Knowledge Networks: A Key Driver for Technological Advancement and Social Progress
}

\author{
George A. Pantazopoulos
}

Submitted: 13 August 2017/Published online: 21 August 2017

(C) ASM International 2017

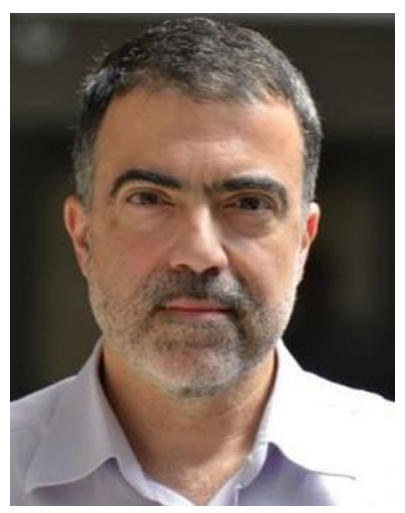

During a very recent event organized by a Hellenic Institute, the basic triangle for economic growth and development was highlighted: education, research, and innovation. In a previous editorial, the importance of the engineering and scientific literature was underlined, together with the role and responsibility of the involved and interested parties, grouped by the readers, authors, reviewers, and editors [1].

The production, preservation, and diffusion of knowledge have become a top priority for our rapidly developing and globalized society. This responsibility can be assigned and distributed among the various levels of society institutions with a hierarchical order. Support and access to knowledge pools and use of modern technology, IT applications, and social media/special interest groups for

G. A. Pantazopoulos ( $\square)$

ELKEME Hellenic Research Centre for Metals S.A., 56th km Athens - Lamia National Road, 32011 Oinofyta Viotias, Greece e-mail: gpantaz@elkeme.vionet.gr

knowledge diffusion are of vital importance. Institutional establishment, leadership drivers, and society vision can lead to the development of strong foundations of knowledge pools and shape their future perspectives. The strong liaisons formed among scientific societies and member activities, the creation of databanks/databases, repositories, and live chatting/Q\&A sessions are powerful options for sharing scientific information in a fast and effective way.

Peer-reviewed Journal and Conference publications remain always on the top of the transfer "vehicles" of sharing scientific information and knowledge and diffusing research results to the "knowledge shareholders." The recently launched open access model brings a new momentum, opening broader channels of knowledge transmission. However, this challenging option requires funding options to be activated and resources to be invested in order to be broadly utilized and further strengthened.

In a rapidly evolving economy, the assurance of sustainability by utilizing and substantiating reliable scientific knowledge is mandatory. Health and environmental protection, rational use of energy and raw materials resources, recycling, quality, and innovation are very widely used terms in modern manufacturing. Academic education and $R \& D$ projects shared among academic communities and industry sector have oriented their strategies toward these requirements which constitute acute society needs.

In our "materials" world, new and advanced materials, smart materials, such as biomimetic materials, lightweight structures, eco-friendly alloys replacing standard ones, failure-resisting components, and self-healing anti-corrosion and anti-wear films are more and more frequently addressed at conferences and symposia. Innovation, covering new and pressing society needs, is an important driver of this triangle to be formed, working also as a funnel, filtrating and consolidating scientific knowledge 
Fig. 1 Simplified schematic showing the interactions among the formation of knowledge networks and the forces driving social progress

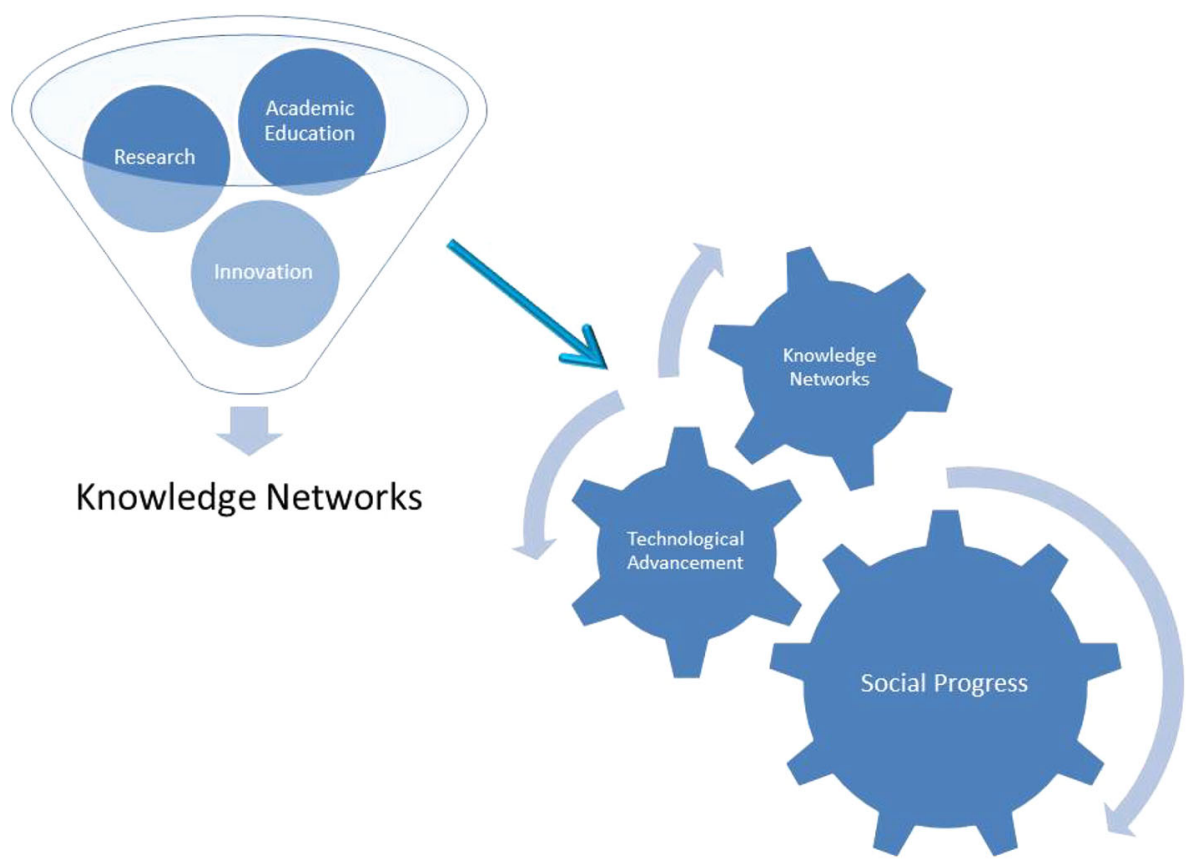

into a continuously growing body, which operates as a "living organization," with "organs," "channels," and "support subsystems," functioning in a network. This is simply illustrated as a schematic in Fig. 1. In the failure analysis community, the access, support, and preservation of knowledge networks are of capital importance. Failure analysis and prevention of failure of critical parts in automotive industry, pipelines of chemical reactors, and building infrastructures require the support and access to knowledge pools and use of fundamental and/or novel scientific information together with, e.g., experimental research, to protect industry and society against hazardous situations. The use of statistical tools and numerical models can be proven of exceptional significance in minimizing risks and enhancing component and structure reliability. Knowledge networks embrace all those options and can be considered as the catalyst and the main gear, driving the progress of society through technological advancement (Fig. 1).

Our roles, as scientific society members, researchers, and technology contributors and team/section leaders, should focus and prioritize the implementation, support, and access to knowledge networks and mentor and train people to become excellent and reliable users, transforming the opportunity into reality and leading society to a bright and challenging future.

\section{Reference}

1. G.A. Pantazopoulos, The value of the engineering literature and the complex role of its contributors. J. Fail. Anal. Prev. 16, 695696 (2016) 